\title{
Transosseous versus transmuscular repair of the posterior soft tissue in primary hip arthroplasty: a meta-analysis
}

\author{
Changjiao Sun ${ }^{1}$, Xiaofei Zhang ${ }^{2}$, Qi Ma' ${ }^{1}$ Ruiyong Du' ${ }^{1}$ Xu Cai ${ }^{1 *+}$ and Huadong Yang ${ }^{1 *+}$
}

\begin{abstract}
Background: During the posterior approach, it has been shown that a significant reduction in dislocation rate can be achieved with the repair of the posterior soft tissue. However, no consensus exists about the best way to perform this repair. This review aimed to compare the transosseous with transmuscular repair of the posterior soft tissue in total hip arthroplasty (THA).
\end{abstract}

Methods: We conducted a meta-analysis to identify studies involving transosseous versus transmuscular repair of the posterior soft tissue in THA in electronic databases, including Web of Science, Embase, PubMed, Cochrane Controlled Trials Register, Cochrane Library, Highwire, CBM, CNKI, VIP, Wanfang database, up to July 2020. Finally, we identified 1417 patients (1481 hips) assessed in seven studies.

Results: Compared with transmuscular repair, transosseous repair resulted in less incidence of dislocation ( $P=$ 0.003), less blood loss during operation $(P<0.00001)$ and lower VAS score within 3 months $(P=0.02)$. There were no significant differences in terms of trochanteric fracture rate $(P=0.56)$, Harris hip score at 3 months $(P=0.35)$ and 6 months $(P=0.89)$, VAS score within 6 months $(P=0.53)$, and operation time $(P=0.70)$ between two groups.

Conclusion: The lower dislocation rate, less blood loss, and lower VAS scores after operation supported transosseous repair's superiority to transmuscular repair. Besides, no additional medical cost and operating time were associated with transosseous repair compared with transmuscular repair. Hence, we recommend that transosseous repair be chosen first by orthopedists when performing reconstruction of the posterior soft tissue in THA via a posterolateral approach. Given the relevant possible biases in our meta-analysis, we required more adequately powered and better-designed RCT studies with long-term follow-up to reach a firmer conclusion.

Keywords: Transosseous, Transmuscular, Dislocation, Bone to tendon, Tendon to tendon, Total hip arthroplasty, Posterolateral approach

\footnotetext{
*Correspondence: suncjdoctor@163.com; yanghuadong2020@sina.com

${ }^{\dagger} \mathrm{Xu}$ Cai and Huadong Yang contributed equally to this work and should be regarded as co- corresponding authors.

'Department of Orthopedic, Beijing Tsinghua Changgung Hospital, School of

Clinical Medicine, Tsinghua University, No.168 Litang Road, Dongxiaokou

Town, Changping District, Beijing 102218, China

Full list of author information is available at the end of the article
}

(c) The Author(s). 2020 Open Access This article is licensed under a Creative Commons Attribution 4.0 International License, which permits use, sharing, adaptation, distribution and reproduction in any medium or format, as long as you give appropriate credit to the original author(s) and the source, provide a link to the Creative Commons licence, and indicate if changes were made. The images or other third party material in this article are included in the article's Creative Commons licence, unless indicated otherwise in a credit line to the material. If material is not included in the article's Creative Commons licence and your intended use is not permitted by statutory regulation or exceeds the permitted use, you will need to obtain permission directly from the copyright holder. To view a copy of this licence, visit http://creativecommons.org/licenses/by/4.0/ The Creative Commons Public Domain Dedication waiver (http://creativecommons.org/publicdomain/zero/1.0/) applies to the data made available in this article, unless otherwise stated in a credit line to the data. 


\section{Introduction}

Several surgical approaches have been implemented in total hip arthroplasty (THA). Among them, the posterolateral approach serves as the most common approach mainly for its minimal trauma to the hip abductors, diminished blood loss, less operative time, excellent visualization of both the acetabulum and proximal femur, and small learning curve [1-6]. However, the hip dislocation rate associated with the posterolateral approach is approximately $2.1-7.5 \%$, higher than the $0-2.3 \%$ rate for the trans-trochanteric or anterolateral approach $[7,8]$, which is attributed to posterior capsule and shortexternal rotator muscle damages [9].

The posterior approach showed that the postoperative dislocation rate was reduced when the posterior capsule and external rotators were carefully repaired in THA via a posterolateral approach [10-12]. In their meta-analysis, Kwon et al. found a relative risk of dislocation eight times greater if no soft tissue repair was performed [13]. However, no consensus exists about the best way to perform this repair. The repair techniques are mainly divided into two categories: (1) transosseous(tendon-to-bone)repair, in which the short external rotator tendon with the posterior capsule is reattached to the greater trochanter transosseous [5, 11, 14-16] and (2) transmuscular (tendon-to-tendon) repair, in which the posterior soft tissue flap is reattached directly to the gluteus medius tendon [4-6, 11, 16-19].

Although previous studies provided adequate reported outcomes of transosseous and transmuscular repair, there is no consensus and evidence-based medicine on the best repair technique of posterior soft tissue (PST). Therefore, in this meta-analysis, our specific purpose is to comprehensively compare transosseous and transmuscular posterior soft tissue repair and give more evidence-based data for orthopedists.

\section{Methods}

The current meta-analysis was registered on PROSPERO (International prospective register of systematic reviews) and the registration number was CRD42020199698.We strictly followed the PRISMA (preferred reporting items for systematic review and meta-analysis) guidelines to conduct this analysis [20] according to the preferred reporting items for systematic reviews and meta-analyses statement.

\section{Search strategy}

We conducted a meta-analysis to identify studies involving transosseous and transmuscular repair of the posterior soft tissue in total hip arthroplasty in electronic databases, including Web of Science, Embase, PubMed, Cochrane, Controlled Trials Register, Cochrane Library, Highwire, CBM, CNKI, VIP, Wanfang database, up to July 2020. The keywords used were "total hip arthroplasty," "total hip replacement," "posterior soft tissue repair," "posterior capsule repair," "Transosseous," "transmuscular," "tendonto-bone" "tendon-to-tendon," "dislocation" in conjunction with Boolean operators "AND" or "OR." Review Manager Software was used to perform the meta-analysis.

\section{Inclusion criteria}

All randomized controlled trials (RCTs) and nonrandomized controlled trials (nRCTs) comparing transosseous and transmuscular repair of the posterior soft tissue in primary THA were identified and included from the search strategy. These studies should meet the following inclusion criteria: (1) The THA procedure was performed for the first time. (2) Transosseous repair of the posterior soft tissue was involved. (3) The comparator was transmuscular repair of the posterior soft tissue in the original comparative study. (4) A posterolateral or posterior approach was used. (5) At least one of the following indexes was reported: dislocation rate, trochanteric fracture, Harris hip score, VAS score, blood loss during operation, and operation time. We also excluded: (1) studies that revision of THA was performed, (2) unclear or incomplete sample data were available, (3) posterior capsule was not mentioned during the procedure, (4) the anterior approach was used, and (5) the postoperative effect was inaccurate.

\section{Data extraction process}

All randomized controlled trials (RCTs) and non- randomized controlled trials (n RCTs) comparing transosseous repair of the posterior soft tissue and transmuscular repair of the posterior soft tissue with primary THA were identified and included from the search strategy. Two researchers independently scanned the titles and abstracts of all literature searched, and they independently extracted the available data from each study. After excluding the trials which did not meet the inclusion criteria, we read the full text of the literature that might meet the inclusion criteria to determine whether this literature ultimately met the inclusion criteria. In the process of crosschecking, disagreements were resolved by discussion to reach consensus. Data were extracted based on the following: (1) research features (i.e., authors, type of study, year of publication, and country), (2) population information (i.e., gender, body mass index [BMI], age follow-up time, and (3) intervention (i.e., diagnosis, the diameter of the femoral head, cup position, diameter of drilled holes). If the necessary results are omitted, we will contact the authors by email or other means to obtain more data if necessary

\section{Assessment of studies}

To assess the methodological quality, we evaluated the nonrandomized studies using the nine-star Newcastle- 
Ottawa scale (NOS), a validated tool suitable for assessing the quality of nonrandomized studies [21]. According to the Cochrane Handbook for Systematic Reviews of Interventions, the methodological quality and basis of the RCTs were assessed as follows: randomization, allocation concealment, blind method, selective reporting, group similarity at baseline, incomplete outcome data, compliance, timing of outcome assessments, and intention-totreat analysis [22]. Two researchers independently assessed the studies, and disagreements between them were resolved through discussions with a third author or consensus.

\section{Statistical analysis}

The $I^{2}$ and $Q$ test was used to evaluate the heterogeneity between studies. $P$ values $\leq 0.1$ or $I^{2}$ value $>50 \%$ suggested a high degree of heterogeneity; thus, we used the randomized-effects model. Otherwise, we used the fixedeffects model [20]. In each study, the odds ratio (OR) and relevant 95\% confidence interval (CI) were commonly used to measure dichotomous variables such as rates of postoperative dislocation and trochanteric fracture. Given that the outcome is rare, reported OR was supposed to approximate RR (relative risk) based on Cornfield's rare disease outcome assumption [23]. The mean difference (MD) or standard MD was used to assess continuous outcomes such as blood loss during operation, Harris hip score, VAS score, and operation time with a $95 \%$ confidence interval (CI). We used statistical algorithms to estimate the standard deviation for those studies that provided only continuous variables for means and range [24]. If $P$ values were less than 0.05 , we considered the results as a statistically significant difference. Sensitivity analysis was used to assess the stability of the results (if necessary), and subgroup analysis was conducted to get more specific and detailed results if the data were available. All statistical analyses were performed using Review Manager (version 5.3 for MAC, the Cochrane Collaboration, the Nordic Cochrane Centre, Copenhagen, 2014).

\section{Results}

\section{Search results}

The literature search and selection process are shown in Fig. 1. Finally, seven publications [25-31] from 2012 to 2019 were included in our meta-analysis. The detailed literature screening process is shown as the PRISMA flow diagram in Fig. 1. Seven hundred ninety-one relevant citations were identified from the databases according to the literature search strategy described earlier. After deleting 218 duplicates, we obtained 573 articles. Upon review of titles and abstracts of the 573 remaining articles, 502 irrelevant clinical studies were excluded. By reading the 71 full-text articles, we excluded another 64 articles for the following reasons such as (systematic) reviews, surgery techniques, none-compare groups, cadaver researches, animal researches, and no useful outcome data. The remaining seven articles were deemed appropriate. Finally, we identified 1417 patients (1481 hips) assessed in (2 RCTs [30, 31] and 5 nRCTs [25-29])

\section{Study characteristics and quality}

The detailed baseline characteristics and general intervention information are presented in Tables 1, 2, and 3 . All the articles were published in English and Chinese between the years 2012 and July 2020 .

\section{Risk of bias assessment}

The methodological quality of the involved studies ranged from 6 to 8 (Table 4). The risk of bias summary and risk of bias graph for RCTs are shown in Table 5 . As a result, the overall quality of the included studies was considered adequate.

\section{Postoperative dislocation rate}

Seven studies assessed the incidence of dislocation. The heterogeneity test $\left(I^{2}=0 \%\right)$ indicated statistical homogeneity among the studies, so the fixed-effect model was used to analyze. The meta-analysis results showed that there was a significant difference in the incidence of postoperative dislocation between the transosseous repair group and the transmuscular repair group (OR 0.4, $95 \%$ CI $0.22-0.73, P=0.003, I^{2}=0 \%$; Fig. 2). To ensure the accuracy and stability of the study, we continued to carry out sensitivity analysis. The sensitivity analysis of the seven works of the literature showed that none of them interfered with the meta-analysis results, which meant this study had excellent stability. The results indicated that compared with transmuscular repair of posterior soft tissue, the transosseous repair is more helpful to reduce the incidence of hip dislocation after primary THA.

\section{Trochanteric fracture}

Two studies reported the Trochanteric fracture rate. The results showed no significant statistical difference between the two groups (RD 0.00, 95\% CI -0.01 to 0.02 , $P=0.56, I^{2}=0 \%$; Fig. 3). According to the heterogeneity test in this study $\left(P=0.83, I^{2}=0 \%\right)$, it was suggested that there was statistical homogeneity among the selected literature in this study, so we chose the fixedeffect model for meta-analysis.

\section{Harris hip score (HHS)}

Two studies reported the Harris hip score (HHS) at 3 months, and two studies reported the HSS at 6 months, and the results showed no significant statistical difference between the two groups at 3 months (MD 2.82, $95 \% \mathrm{CI}-3.14$ to $8.78, P=0.35, I^{2}=72 \%$; Fig. 4 ), and at 


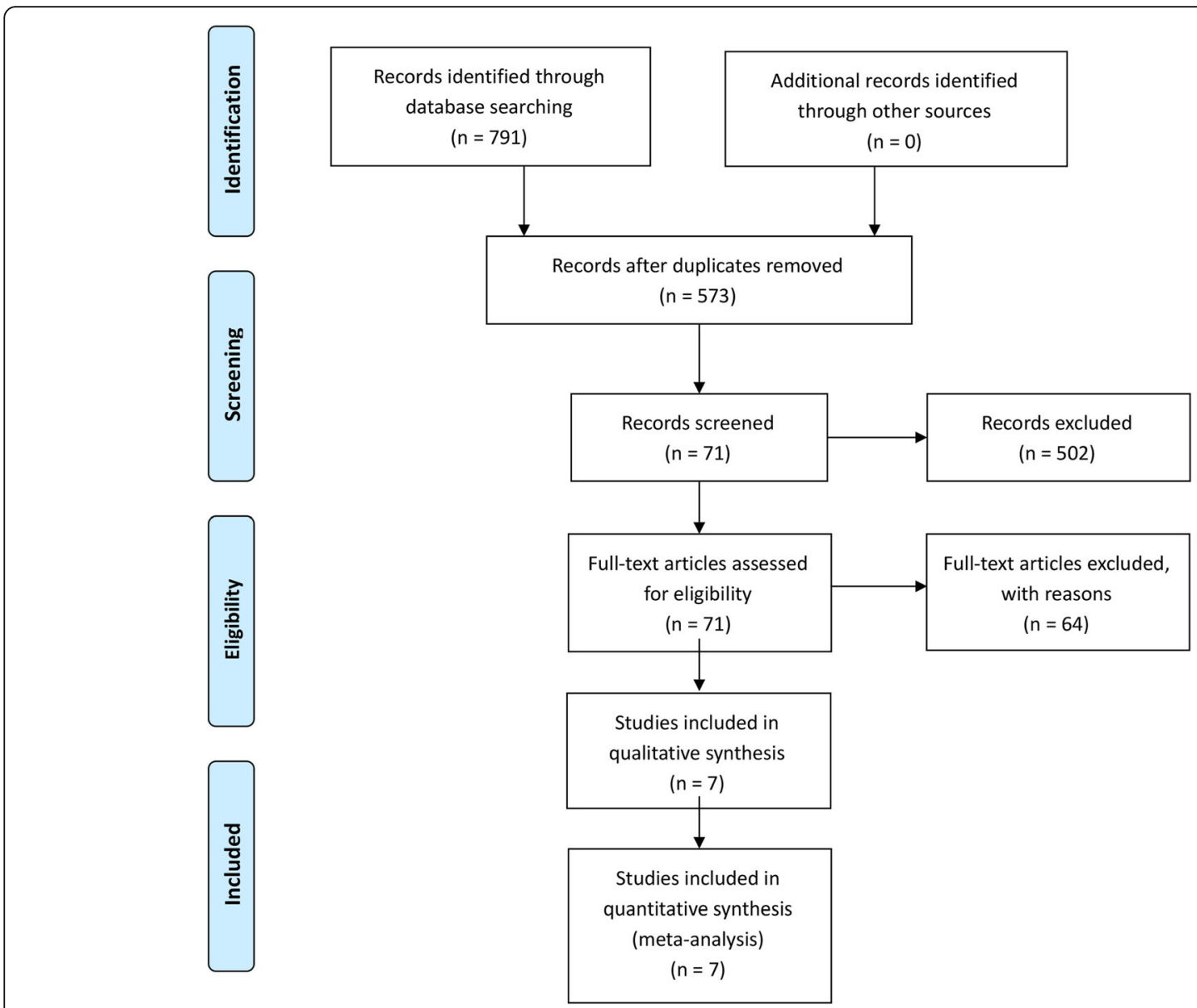

Fig. 1 The search results and selection procedure. Seven hundred ninety-one relevant citations were identified from the databases according to the literature search strategy described earlier. After deleting 218 duplicates, we obtained 573 articles. Upon review of titles and abstracts of the 573 remaining articles, 502 irrelevant clinical studies were excluded. By reading the 71 full-text articles, we excluded another 64 articles for the following reasons such as (systematic) reviews, surgery techniques, none-compare groups, cadaver researches, animal researches, and no useful outcome data. The remaining seven articles were deemed appropriate. Finally, we identified 1417 patients (1481 hips) assessed in (2 RCTs [30, 31] and 5 nRCTs

Table 1 Summary of studies characteristics

\begin{tabular}{|c|c|c|c|c|}
\hline Author & Year & Country & Design & $\begin{array}{l}\text { Follow-up time } \\
\text { (transosseous / } \\
\text { transmuscular) } \\
\text { (months) }\end{array}$ \\
\hline Cai et al. & 2013 & China & Retrospective study & $6 / 6$ \\
\hline Cao et al. & 2012 & China & Retrospective study & $6 / 6$ \\
\hline Liu et al. & 2018 & China & Retrospective study & $6 / 6$ \\
\hline Moon et al. & 2018 & South Korea & $\mathrm{RCT}$ & $28 / 29$ \\
\hline Wu et al. & 2019 & China & Retrospective study & $6 / 6$ \\
\hline Shen et al. & 2015 & China & Retrospective study & $19.74 / 22.37$ \\
\hline Spaas et al. & 2015 & Netherlands & $\mathrm{RCT}$ & $12 / 12$ \\
\hline
\end{tabular}

Abbreviations: $R C T$ randomized controlled trials. Summary of studies characteristics including a year of publication, country, design, and follow-up time 
Table 2 Summary of patient demographic details for each study

\begin{tabular}{llllll}
\hline Author & Patients & THAs & Age (years) & Female (\%) & BMI (kg/m $\mathbf{m}^{\mathbf{2}}$ \\
\hline Cai et al. & $164 / 98$ & $213 / 104$ & $71.8 / 66.3$ & $56.1 / 57.1$ & $\mathrm{NA}$ \\
Cao et al. & $30 / 30$ & $30 / 30$ & $\mathrm{NA}$ & $\mathrm{NA}$ & $\mathrm{NA}$ \\
Liu et al. & $40 / 40$ & $6 / 6$ & $74.5 / 74.7$ & $47 / 50$ & $\mathrm{NA}$ \\
Moon et al. & $85 / 73$ & $87 / 80$ & $69 / 72$ & $72.4 / 63.8$ & $24.7 / 24.1$ \\
Wu et al. & $46 / 41$ & $46 / 41$ & $57.7 / 60.9$ & $56.5 / 53.7$ & $26 / 25$ \\
Shen et al. & $126 / 179$ & $126 / 179$ & $51.55 / 53.32$ & $40.5 / 40.2$ & $\mathrm{NA}$ \\
Spaas et al. & $219 / 246$ & $219 / 246$ & $71 / 69$ & $64 / 66$ & $\mathrm{NA}$ \\
\hline
\end{tabular}

Abbreviations: BMI body mass index. Summary of patient demographic information for each study including number of THAs/patients, gender, age, and BMI

6 months (MD 0.16, 95\% CI -2.06 to $2.37, P=0.89, I^{2}$ $=78 \%$; Fig. 5) According to the heterogeneity test in this study $\left(P=0.06, I^{2}=72 \%\right),\left(P=0.03, I^{2}=78 \%\right)$, it was suggested that there was heterogeneity among the selected literature in this study, so we chose the random effect model for meta-analysis.

\section{VAS score}

Two studies reported the VAS score within 3 months and 6 months. The results showed significant statistical difference between the 2 groups within 3 months (MD 0.49, $95 \% \mathrm{CI}-0.91$ to $-0.07, P=0.02, I^{2}=85 \%$; Fig. 5 ) and no significant statistical difference between the 2 groups within 6 months (MD -0.12 , 95\% CI -0.48 to
0.25, $P=0.53, I^{2}=87 \%$; Fig. 5) According to the heterogeneity test in this study $\left(P=0.009, I^{2}=85 \%\right)$, $\left(P=0.005, I^{2}=87 \%\right)$, it was suggested that there was heterogeneity among the selected literatures in this study, so we chose the random effect model for meta-analysis.

\section{Operation time}

Three studies reported the operation time. The results showed no significant statistical difference between the 2 groups (MD - 1.02, 95\% CI -6.1 to $4.06, P=0.70, I^{2}=$ 45\%; Fig. 6). According to the heterogeneity test in this study $\left(P=0.16, I^{2}=45 \%\right)$, it was suggested that there was statistical homogeneity among the selected literature

Table 3 The detailed characteristics of general intervention information

\begin{tabular}{|c|c|c|c|c|c|c|c|}
\hline Author & Cai et al. & Cao et al. & Liu et al. & Moon et al. & Wu et al. & Shen et al. & Spaas et al. \\
\hline \multicolumn{8}{|l|}{ Transosseous /transmuscular } \\
\hline \multicolumn{8}{|l|}{ Diagnosis } \\
\hline Osteonecrosis of femoral head & $0 / 0$ & NA & NA & $51 / 46$ & $27 / 23$ & $20 / 34$ & $0 / 0$ \\
\hline Hip osteoarthritis & $213 / 104$ & NA & NA & $35 / 32$ & $7 / 2$ & $89 / 124$ & $219 / 246$ \\
\hline Femoral neck fracture & $0 / 0$ & NA & NA & $0 / 0$ & $7 / 13$ & $0 / 0$ & $0 / 0$ \\
\hline Developmental dysplasia of hip & $0 / 0$ & NA & NA & $0 / 0$ & $5 / 3$ & $0 / 0$ & $0 / 0$ \\
\hline Traumatic arthritis & $0 / 0$ & NA & NA & $0 / 0$ & $0 / 0$ & $6 / 13$ & $0 / 0$ \\
\hline Rheumatoid arthritis & $0 / 0$ & NA & NA & $1 / 2$ & $0 / 0$ & $11 / 8$ & $0 / 0$ \\
\hline Femoral head (mm) & & & & 32 or 36 & & & \\
\hline 24 & NA & NA & NA & & $0 / 1$ & $0 / 0$ & $0 / 0$ \\
\hline 28 & NA & NA & NA & & $2 / 6$ & $126 / 179$ & $0 / 0$ \\
\hline 32 & NA & NA & NA & & $16 / 18$ & $0 / 0$ & $0 / 0$ \\
\hline 36 & NA & NA & NA & & $25 / 15$ & $0 / 0$ & $219 / 246$ \\
\hline 40 & NA & NA & NA & & $3 / 1$ & $0 / 0$ & $0 / 0$ \\
\hline \multicolumn{8}{|l|}{ Cup position } \\
\hline Anteversion $\left({ }^{\circ}\right)$ & NA & NA & NA & 20.2/19.5 & $14 / 14.3$ & $14.51 / 14.56$ & NA \\
\hline Abduction $\left({ }^{\circ}\right)$ & NA & NA & NA & $42.5 / 41.7$ & $36.5 / 37$ & $44.97 / 45.21$ & NA \\
\hline Diameter of drilled holes $(\mathrm{mm})$ & NA & 2.3 & 2 & NA & 2 & 2 & 2.3 \\
\hline Tranexamic acid use & NA & NA & NA & NA & Yes & NA & NA \\
\hline
\end{tabular}

The detailed characteristics of general intervention information, including diagnosis, the diameter of the femoral head, cup position, diameter of drilled holes, tranexamic acid use 
Table 4 Risk-of-bias assessment for the studies included in the meta-analysis (NOS)

\begin{tabular}{|c|c|c|c|c|c|c|c|c|c|}
\hline \multirow{2}{*}{$\begin{array}{l}(\mathrm{nRCT}) \\
\text { Study }=6\end{array}$} & \multicolumn{4}{|c|}{ Selection } & \multirow{2}{*}{$\begin{array}{l}\text { Comparability } \\
\text { Item } 5\end{array}$} & \multicolumn{3}{|c|}{ Outcome/exposure } & \multirow[t]{2}{*}{ Score } \\
\hline & Item 1 & Item 2 & Item 3 & Item 4 & & Item 6 & Item 7 & Item 8 & \\
\hline Cai 2012 & $*$ & & $*$ & * & * & * & & $*$ & 6 \\
\hline Liu 2018 & * & & * & * & * & * & & * & 6 \\
\hline Nmed 2019 & * & * & * & * & * & * & & * & 7 \\
\hline Shen 2015 & * & * & * & * & * & * & & * & 7 \\
\hline Wu 2019 & $*$ & * & * & $*$ & * & * & & * & 7 \\
\hline Cao 2012 & * & * & * & * & * & * & * & * & 8 \\
\hline
\end{tabular}

The methodological quality of the involved studies ranged from 6 to 8

in this study, so we chose the fixed-effect model for meta-analysis.

\section{Blood loss during operation}

Two studies reported the Blood loss during operation. The results showed a significant statistical difference between the two groups (MD - $112.3895 \% \mathrm{CI}-136.58$ to - 88.17, $P<0.00001, I^{2}=76 \%$, Fig. 7). According to the heterogeneity test in this study $\left(P<0.00001, I^{2}=76 \%\right)$, it was suggested that there was heterogeneity among the selected literature in this study, so we chose the random effect model for meta-analysis. The results indicated that compared with transmuscular repair of posterior soft tissue, transosseous repair has less blood loss during operation.

\section{Discussion}

Although uncommon, postoperative hip dislocation after arthroplasty is a complication with serious consequences. The chance of dislocation is influenced by multiple factors [1,32-37], which could be mainly divided into three aspects : (1) patient-related factors, (2) surgery related factors, and (3) postoperative management factors. Patient-related factors include age $(>80$ years) [38], gender(female), original diseases such as mental illness, neuromuscular disease, Parkinson's disease, and surgery history of the hip [39]. Surgeryrelated factors included surgery approach [40], surgeon experience [17], prosthesis position [40], offset [41], femoral head diameter [42], prosthesis design [43], and soft tissue repair $[12,44]$. Postoperative management was also important for patients after THA. Patients should be informed to avoid doing high-risk postures [45].

Of these factors, surgeons can control surgical-related factors. In the posterolateral or posterior approach, which may induce posterior capsule and short external rotator muscle damage increasing the patient's vulnerability to postoperative dislocation [46]. Researchers have attempted to identify methods for reducing the postoperative dislocation rate by repairing the posterior structures, including the posterior capsule and short external rotator tendon.

Three meta-analyses [12, 44, 47] found a relatively higher risk of dislocation more significant if no soft tissue repair was performed. There are two ways of posterior repair of soft tissue. Some surgeons performed a transosseous repair of soft tissue by drilling holes [14-16, 48]. Several authors performed soft tissue repair without drilling holes [17-19]. Both ways of repair showed decreasing dislocation rates [12, 44].

Some authors $[25,30]$ compared the dislocation rate between transosseous and transmuscular repair and reported that transosseous and transmuscular repair were equally effective techniques without significant differences in dislocation rates. They believed that transmuscular repair was easy to perform, and the elastic suture site had the potential to avoid tearing of the reconstructed posterior soft tissue during healing. Drilling holes could be 1 of the factors causing a longer operation time in the transosseous group. Passing sutures through the trochanter by drilled holes can locally weaken the bone, which may cause the failure

Table 5 Methodological assessment according to six domains of potential biases (Cochrane Risk of Bias Tool)

\begin{tabular}{llllllll}
\hline RCT Study =2 & $\begin{array}{l}\text { Random } \\
\text { sequence } \\
\text { generation }\end{array}$ & $\begin{array}{l}\text { Allocation } \\
\text { concealment }\end{array}$ & $\begin{array}{l}\text { Blinding of } \\
\text { participants } \\
\text { and personnel }\end{array}$ & $\begin{array}{l}\text { Blinding of } \\
\text { outcome } \\
\text { assessment }\end{array}$ & $\begin{array}{l}\text { Incomplete } \\
\text { outcome data }\end{array}$ & $\begin{array}{l}\text { Selective } \\
\text { reporting }\end{array}$ & $\begin{array}{l}\text { Other } \\
\text { bias }\end{array}$ \\
\hline Moon $\mathbf{2 0 1 8}$ & Low & Low & Low & Low & Low & Low & Unclear \\
Spaans 2015 & High & High & Unclear & Low & Low & Low & Unclear \\
\hline
\end{tabular}




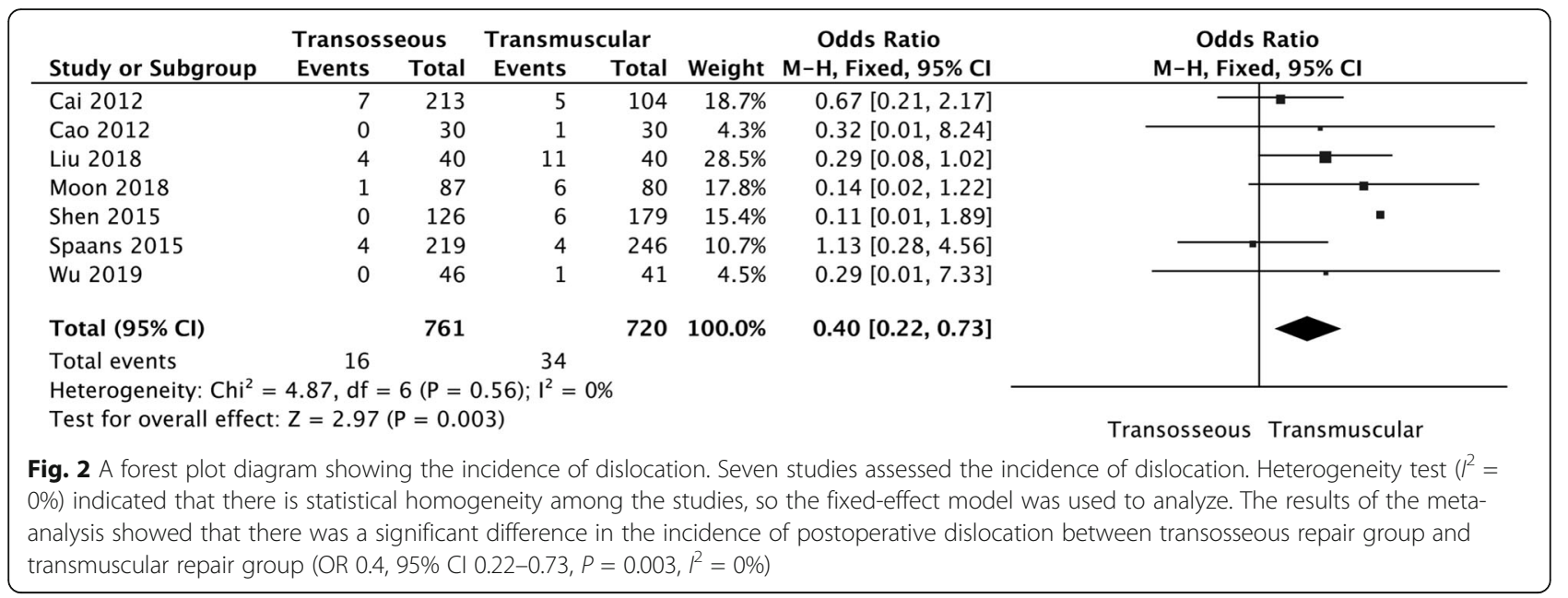

of the repair and trochanteric avulsion fractures [6]. However, some authors believe transosseous reapproximation of the capsule and/or short external rotators to the posterior aspect of the greater trochanter through drilled holes in the bone is thought to give better strength and probably a more anatomical repair [11, 14-16]. Moon et al. [31] reported that suture failure was observed less frequently in the transosseous group (18.4\%) than in the transmuscular repair group (65\%). The dislocation rate was significantly higher in the transmuscular repair group compared with the transosseous group.

It considered the uncertainty and controversy about the influence of transosseous and transmuscular posterior soft tissue repair on the incidence of hip dislocation following primary THA. We sought to evaluate the body of evidence linking transosseous and transmuscular repair with the risk of hip dislocation following primary THA carrying out a comprehensive systematic review of RCTs and observational studies. To our knowledge, this is the first meta-analysis comparing the transosseous repair and transmuscular repair of posterior soft tissue in primary THA. This meta-analysis included seven studies (2 RCTs and five nRCTs) that analyzed 1417 patients (1481 hips) and compared the transosseous repair group's clinical effectiveness and the transmuscular repair group. Lower dislocation rate, less blood loss during operation, and lower pain scores within 3 months supported the superiority of transosseous repair to transmuscular repair based on the existing evidence base. There was no significant difference in trochanteric fracture rate, operation time, HHS score, and VAS score within 6 months between two groups.

In a biomechanical study, Sioen et al. [49] revealed that the mechanical strength of transosseous repair was superior to that of transmuscular repair. They measured the torsion strength and rotation angle of the hip under three repair conditions, including no repair, transosseous repair, and transmuscular repair. They found that the transosseous repair group's torsion strength was four times as much as that when the repair was not done and twice that of the transmuscular repair group. The transosseous repair group's hip rotation angle was increased by $83 \%$ compared to that in the no repair group and by $46 \%$ in the transmuscular group. Moon et al. [31] provided reliable clinical data for transosseous and transmuscular repair. They compared the rates of repair failure after the two repair techniques. Of the 167 hips included, 87 hips underwent transosseous repair, and 80 hips underwent transmuscular repair. Suture failure was

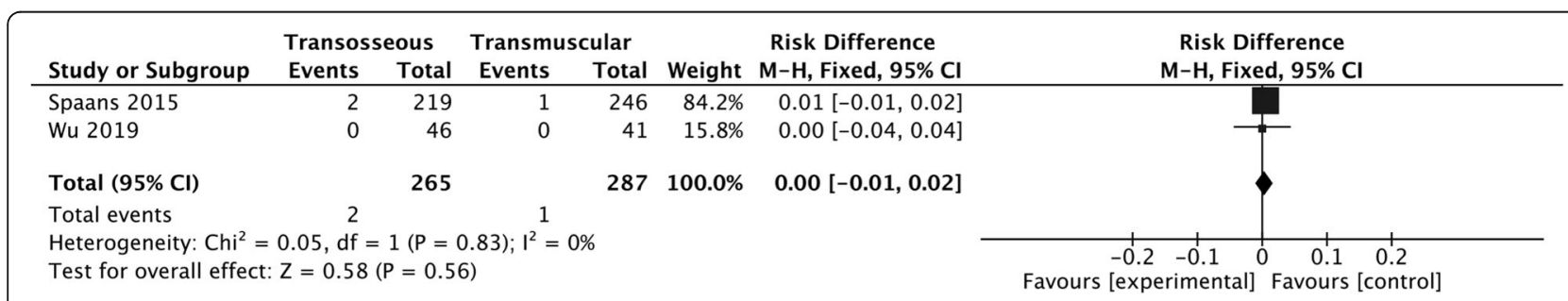

Fig. 3 A forest plot diagram showing Trochanteric fracture rate. Two studies reported the Trochanteric fracture rate. The results showed no significant statistical difference between the 2 groups ( $\mathrm{RD} 0.00,95 \% \mathrm{Cl}-0.01$ to $0.02, P=0.56, P^{2}=0 \%$ ) 


\begin{tabular}{|c|c|c|c|c|c|c|c|c|c|}
\hline \multirow[b]{2}{*}{ Study or Subgroup } & \multicolumn{3}{|c|}{ Transosseous } & \multicolumn{3}{|c|}{ Transmuscular } & \multirow{3}{*}{ Weight } & \multirow{2}{*}{$\begin{array}{l}\text { Mean Difference } \\
\text { IV, Random, } 95 \% \mathrm{CI}\end{array}$} & \multirow{2}{*}{$\begin{array}{c}\text { Mean Difference } \\
\text { IV, Random, } 95 \% \mathrm{CI}\end{array}$} \\
\hline & Mean & SD & Total & Mean & SD & Total & & & \\
\hline \multicolumn{9}{|l|}{ 1.3.1 3 month } & \\
\hline Liu 2018 & 75.4 & 11.7 & 40 & 69.3 & 11.3 & 40 & $12.1 \%$ & $6.10[1.06,11.14]$ & - \\
\hline $\begin{array}{l}\text { Spaans } 2015 \\
\text { Subtotal }(95 \% \mathrm{Cl})\end{array}$ & 81 & 20 & $\begin{array}{l}219 \\
259\end{array}$ & 81 & 22 & $\begin{array}{l}246 \\
286\end{array}$ & $\begin{array}{l}17.4 \% \\
29.6 \%\end{array}$ & $\begin{array}{c}0.00[-3.82,3.82] \\
2.82[-3.14,8.78]\end{array}$ & $\sqrt{1}$ \\
\hline \multicolumn{10}{|c|}{$\begin{array}{l}\text { Heterogeneity: } \text { Tau }^{2}=13.40 ; \mathrm{Chi}^{2}=3.57, \mathrm{df}=1(\mathrm{P}=0.06) ; \mathrm{I}^{2}=72 \% \\
\text { Test for overall effect: } Z=0.93(P=0.35)\end{array}$} \\
\hline \multicolumn{10}{|l|}{1.3 .26 month } \\
\hline Liu 2018 & 90.4 & 2.9 & 40 & 89.2 & 2.4 & 40 & $37.5 \%$ & $1.20[0.03,2.37]$ & 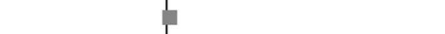 \\
\hline $\begin{array}{l}\text { Wu } 2019 \\
\text { Subtotal }(95 \% \mathrm{Cl})\end{array}$ & 91.78 & 4.599 & $\begin{array}{l}46 \\
86\end{array}$ & 92.85 & 3.554 & $\begin{array}{l}41 \\
81\end{array}$ & $\begin{array}{l}32.9 \% \\
70.4 \%\end{array}$ & $\begin{array}{r}-1.07[-2.79,0.65] \\
0.16[-2.06,2.37]\end{array}$ & 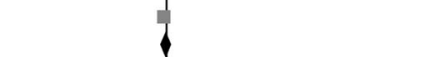 \\
\hline \multicolumn{10}{|c|}{$\begin{array}{l}\text { Heterogeneity: } \mathrm{Tau}^{2}=2.02 ; \mathrm{Chi}^{2}=4.59, \mathrm{df}=1(\mathrm{P}=0.03) ; \mathrm{I}^{2}=78 \% \\
\text { Test for overall effect: } \mathrm{Z}=0.14(\mathrm{P}=0.89)\end{array}$} \\
\hline Total $(95 \% \mathrm{Cl})$ & & & 345 & & & 367 & $100.0 \%$ & $0.84[-1.24,2.91]$ & 4 \\
\hline \multicolumn{8}{|c|}{$\begin{array}{l}\text { Heterogeneity: } \mathrm{Tau}^{2}=2.64 ; \mathrm{Chi}^{2}=9.31, \mathrm{df}=3(P=0.03) ; \mathrm{I}^{2}=68 \% \\
\text { Test for overall effect: } Z=0.79(P=0.43) \\
\text { Test for subgroup differences: } \mathrm{Chi}^{2}=0.67, \mathrm{df}=1(P=0.41), \mathrm{I}^{2}=0 \%\end{array}$} & -100 & \begin{tabular}{l|cc}
1 & 1 \\
-50 & 0 & 50 \\
Transosseous & Transmuscular
\end{tabular} \\
\hline \multicolumn{10}{|c|}{$\begin{array}{l}\text { Fig. } 4 \text { A forest plot diagram showing Harris hip score (HHS).Two studies reported the Harris hip score (HHS) at } 3 \text { months and two studies } \\
\text { reported the HSS at } 6 \text { months, and the results showed no significant statistical difference between the } 2 \text { groups at } 3 \text { months (MD } 2.82,95 \% \mathrm{Cl}- \\
\left.3.14 \text { to } 8.78, P=0.35, P^{2}=72 \% \text { ) and at } 6 \text { months (MD } 0.16,95 \% \mathrm{Cl}-2.06 \text { to } 2.37, P=0.89, P^{2}=78 \%\right)\end{array}$} \\
\hline
\end{tabular}

observed less frequently in the transosseous repair group (18.4\%) than in the transmuscular repair group (65\%). These biomechanical features and the low-frequency suture failure of the transosseous repair group, seem to contribute to the decreased dislocation rate in transosseous repair group more than the transmuscular repair group in our meta-analysis

Zhou et al. [47] reported that drilling holes in the greater trochanter would reduce bone strength and increase fracture risk. Intraoperative periprosthetic fractures are also mentioned as a rare complication of uncemented total hip replacement. However, our data showed there were no significant differences in terms of the trochanter fracture rate. White et al. [6] revealed that when $2.7-\mathrm{mm}$ bone holes reconstructed the posterior, the greater trochanteric fracture was $0.9 \%$. They believed that greater trochanteric fractures could be avoided by reducing the diameter of bone holes. Osmani et al. [50] reduced the holes to $2.3 \mathrm{~mm}$, and no greater trochanteric fracture was observed in 150 patients during follow-up. The diameter of the bone holes in our data is no more than 2.3. We believed that reasonable holes had no significant effect on bone strength, and the bone holes were strong enough to resist the pull of the sutures.

Some surgeons believe transosseous repair with drilling holes may cause a longer operation time. However, no significant difference was observed in terms of operation time between the two groups in our meta-analysis. Multiple factors influence the operation time. More prospective randomized trials investigating operation is needed to confirm the results.

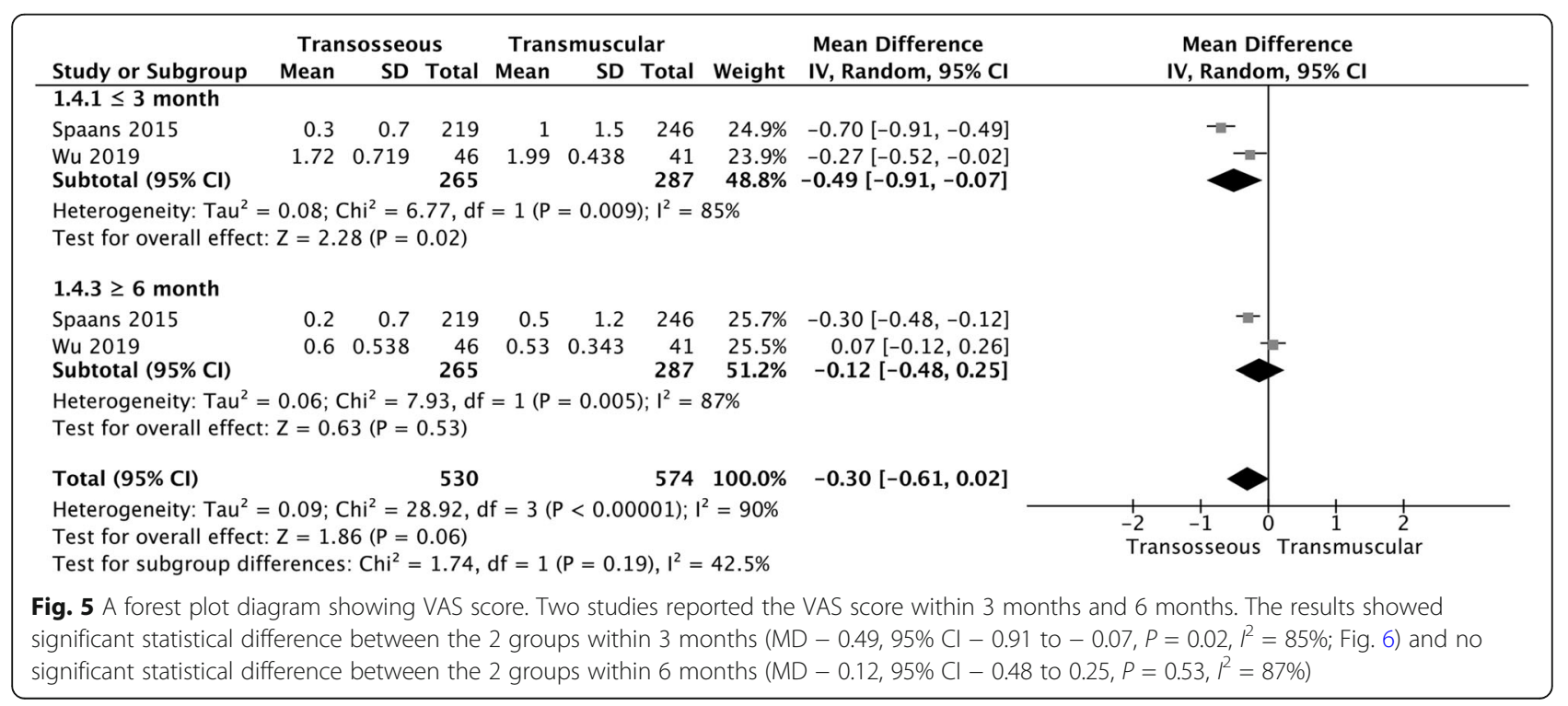




\begin{tabular}{|c|c|c|c|c|c|c|c|c|c|}
\hline \multirow[b]{2}{*}{ Study or Subgroup } & \multicolumn{3}{|c|}{ Transosseous } & \multicolumn{3}{|c|}{ Transmuscular } & \multicolumn{2}{|r|}{ Mean Difference } & \multirow{2}{*}{$\begin{array}{l}\text { Mean Difference } \\
\text { IV, Fixed, } 95 \% \mathrm{CI}\end{array}$} \\
\hline & Mean & SD & Total & Mean & SD & Total & Weight & IV, Fixed, $95 \% \mathrm{Cl}$ & \\
\hline Liu 2018 & 78.8 & 13.9 & 40 & 80.1 & 15.4 & 40 & $62.4 \%$ & $-1.30[-7.73,5.13]$ & \\
\hline Moon 2018 & 133.5 & 35 & 87 & 129.2 & 28.75 & 80 & $27.5 \%$ & $4.30[-5.38,13.98]$ & \\
\hline Wu 2019 & 116.5 & 37.1 & 46 & 130.3 & 38.9 & 41 & $10.1 \%$ & $-13.80[-29.82,2.22]$ & \\
\hline Total $(95 \% \mathrm{Cl})$ & & & 173 & & & 161 & $100.0 \%$ & $-1.02[-6.10,4.06]$ & \\
\hline \multicolumn{9}{|c|}{$\begin{array}{l}\text { Heterogeneity: } \mathrm{Chi}^{2}=3.61, \mathrm{df}=2(\mathrm{P}=0.16) ; \mathrm{I}^{2}=45 \% \\
\text { Test for overall effect: } Z=0.39(P=0.70)\end{array}$} & $\begin{array}{cccc}-50 & -25 & 0 & 25 \\
& \text { Transosseous } & \text { Transmuscular }\end{array}$ \\
\hline
\end{tabular}

As for blood loss, our data showed less blood loss during operation in the transosseous repair group. The posterior soft tissue flap is reattached directly to the gluteus medius tendon with the transmuscular repair method. This tendon to tendon or muscle repair may cause more blood loss during the operation.

Harris hip score is frequently used to assess the outcome and effectiveness of total hip arthroplasty. In our meta-analysis, no significant difference was observed in terms of HSS at 3 months and 6 months between two groups. We believe that the main advantage of posterior reconstruction, either with the transosseous repair or transosseous is the reconstruction of biofeedback. The patient will notice that too much internal rotation of the hip could lead to dislocation. In that objective, it would seem logical that the HSS of transmuscular and transosseous repair is comparable.

Our data also showed that the VAS scores within 3 months after surgery were significantly lower in the transosseous group than those in the transmuscular group. The difference disappeared within 6 months after surgery. According to these results, transosseous repair appears to present superiority in early pain. We think the reason may be that the posterior soft tissue was displaced from their normal anatomical position with transmuscular repair. Additional strain in the reconstructed soft tissue would occur when the affected hip rotated internally, which might generate the difference in early pain between the two repair techniques.

The limitations of this study are as follows. Firstly, we only included two randomized controlled trials; the other five studies were observational studies, which may have reduced the quality of the evidence for this meta- analysis. Although we have included all related studies thus far and tried to collect more data to make this meta-analysis and assess its effect, more prospective randomized trials investigating dislocation incidence and other clinical parameters are needed to confirm the results and conclusions. Secondly, the follow-up time was short that long-term consequences concerning transosseous repair and transmuscular repair were unknown. Thirdly, there is diversity in the size of the femoral head, and the detailed data is not clear in most included articles. We cannot perform a subgroup analysis to see if the dislocations rates differed with studies reporting larger head sizes versus smaller head sizes. Fourth, many other factors affect the rate of dislocation of a THA. There is diversity in the follow-up time, patient factors, surgeon factors, and so on, so the heterogeneity is increasing among included studies.

\section{Conclusion}

In conclusion, the lower dislocation rate, less blood loss, and lower VAS score early after operation supported the superiority of transosseous repair to transmuscular repair. Besides, no additional medical cost and operating time were associated with transosseous repair compared with transmuscular repair. Hence, we recommend that transosseous repair could be chosen first by orthopedists when performing reconstruction of the posterior soft tissue in THA via a posterior or posterolateral approach. Given the relevant possible biases in our meta-analysis, more adequately powered and better-designed RCT studies with long-term follow-up were required to reach a firmer conclusion.

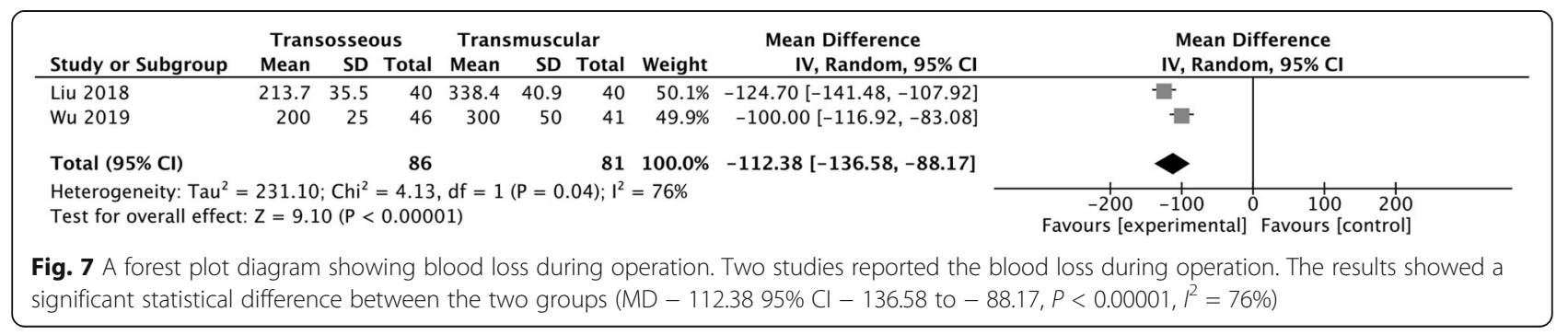




\section{Abbreviations}

Cls: Confidence intervals; RCTs: Randomized controlled trials; RR: Risk ratio; OR: Odds ratio; VMD: Weighted mean difference; THA: Total hip arthroplasty; BMI: Body mass index

\section{Acknowledgements}

Not applicable.

\section{Authors' contributions}

Changjiao Sun, Xu Cai, and Huadong Yang: conceptualization data curation; formal analysis, roles/writing —original draft; writing — review and editing. Qi Ma and Ruiyong Du: data collection; investigation; methodology. Xiaofei Zhang: resources; software. Xu Cai and Huadong Yang: (co-corresponding author): supervised the whole study. All authors read and approved the final manuscript.

\section{Funding}

None.

\section{Availability of data and materials}

The datasets generated during and/or analyzed during the current study are available from the corresponding author on reasonable request.

\section{Ethics approval and consent to participate}

Not applicable.

\section{Consent for publication}

Not applicable.

\section{Competing interests}

The authors declare that they have no competing interests.

\section{Author details}

'Department of Orthopedic, Beijing Tsinghua Changgung Hospital, School of Clinical Medicine, Tsinghua University, No.168 Litang Road, Dongxiaokou Town, Changping District, Beijing 102218, China. ${ }^{2}$ Department of Clinical Epidemiology and Biostatistics, Beijing Tsinghua Changgung Hospital, School of Clinical Medicine, Tsinghua University, No.168 Litang Road, Dongxiaokou Town, Changping District 102218, Beijing, China.

\section{Received: 7 September 2020 Accepted: 10 November 2020}

\section{Published online: 19 November 2020}

\section{References}

1. Petis $S$, Howard JL, Lanting BL, Vasarhelyi EM. Surgical approach in primary total hip arthroplasty: anatomy, technique and clinical outcomes. Can J Surg. 2015;58:128-39.

2. Hedlundh $\mathrm{U}$, Hybbinette $\mathrm{CH}$, Fredin $\mathrm{H}$. Influence of surgical approach on dislocations after Charnley hip arthroplasty. J Arthroplast. 1995;10:609-14.

3. Berstock JR, Blom AW, Beswick AD. A systematic review and meta-analysis of the standard versus mini-incision posterior approach to total hip arthroplasty. J Arthroplast. 2014;29:1970-82.

4. Pellicci PM, Bostrom M, Poss R. Posterior approach to total hip replacement using enhanced posterior soft tissue repair. Clin Orthop Relat Res. 1998:2248. https://doi.org/10.1097/00003086-199810000-00023.

5. Chiu FY, Chen CM, Chung TY, Lo WH, Chen TH. The effect of posterior capsulorrhaphy in primary total hip arthroplasty: a prospective randomized study. J Arthroplast. 2000;15:194-9.

6. White RE Jr, Forness TJ, Allman JK, Junick DW. Effect of posterior capsular repair on early dislocation in primary total hip replacement. Clin Orthop Relat Res. 2001:163-7. https://doi.org/10.1097/00003086-200112000-00019.

7. Woo RY, Morrey BF. Dislocations after total hip arthroplasty. J Bone Jt. Surg Am. 1982;64:1295-306.

8. Robinson RP, Robinson $\mathrm{HJ} J$ r, Salvati EA. Comparison of the transtrochanteric and posterior approaches for total hip replacement. Clin Orthop Relat Res. 1980:143-7.

9. Ritter MA, Harty LD, Keating ME, Faris PM, Meding JB. A clinical comparison of the anterolateral and posterolateral approaches to the hip. Clin Orthop Relat Res. 2001:95-9. https://doi.org/10.1097/00003086-200104000-00016.
10. TV, S., MM, K., JC, B., HGM, C. \& JM, B. The "capsular noose": A new capsular repair technique to diminish dislocation risk after the posterior approach total hip arthroplasty. Int. J. Surg. Open. 2019;17:8-14.

11. Tarasevicius $\mathrm{S}$, Robertsson $\mathrm{O}$, Wingstrand $\mathrm{H}$. Posterior soft tissue repair in total hip arthroplasty: a randomized controlled trial. Orthopedics. 2010;33:871.

12. Zhang D, et al. Effectiveness and safety of the posterior approach with soft tissue repair for primary total hip arthroplasty: a meta-analysis. Orthop Traumatol Surg Res. 2015;101:39-44.

13. Kwon MS, et al. Does surgical approach affect total hip arthroplasty dislocation rates? Clin Orthop Relat Res. 2006:447:34-8.

14. Morrey BF. Instability after total hip arthroplasty. Orthop Clin North Am. 1992:23:237-48

15. Shaw JA. Experience with a modified posterior approach to the hip joint. A technical note. J Arthroplast. 1991;6:11-8.

16. Suh KT, Park BG, Choi YJ. A posterior approach to primary total hip arthroplasty with soft tissue repair. Clin Orthop Relat Res. 2004:162-7. https://doi.org/10.1097/00003086-200401000-00026.

17. Tsai SJ, Wang CT, Jiang CC. The effect of posterior capsule repair upon postoperative hip dislocation following primary total hip arthroplasty. BMC Musculoskelet Disord. 2008:9:29.

18. Hedley AK, Hendren DH, Mead LP. A posterior approach to the hip joint with complete posterior capsular and muscular repair. J Arthroplast. 1990; 5(Suppl):S57-66

19. Weeden SH, Paprosky WG, Bowling JW. The early dislocation rate in primary total hip arthroplasty following the posterior approach with posterior softtissue repair. J Arthroplast. 2003;18:709-13.

20. Moher D, Liberati A, Tetzlaff J, Altman DG. Preferred reporting items for systematic reviews and meta-analyses: the PRISMA statement. Int I Surg. 2010:8:336-41.

21. Stang A. Critical evaluation of the Newcastle-Ottawa scale for the assessment of the quality of nonrandomized studies in meta-analyses. Eur J Epidemiol. 2010;25:603-5.

22. Higgins JP, et al. The Cochrane Collaboration's tool for assessing risk of bias in randomised trials. BMJ. 2011;343:d5928.

23. Cornfield J. A method of estimating comparative rates from clinical data; applications to cancer of the lung, breast, and cervix. J Natl Cancer Inst. 1951:11:1269-75.

24. Hozo SP, Djulbegovic B, Hozo I. Estimating the mean and variance from the median, range, and the size of a sample. BMC Med Res Methodol. 2005:5:13.

25. Wu, F. Mm., Yin, P., Yu, X., Liu, G. \& Zheng, W. Comparison of two posterior soft tissue repair techniques to prevent dislocation after total hip arthroplasty via the posterolateral approach. J Invest Surg 1-9 (2019) doi: https://doi.org/10.1080/08941939.2019.1651922.

26. Cai $\mathrm{S}$, et al. Effects of different soft tissue repair methods on early dislocation rate after primary total hip arthroplasty. Orthop. J. China. 2013; 21:1725-8.

27. Cao X, Xiao C, Lv R, Li X. A comparative study of three different methods to reconstruct the posterior joint capsule of the hip to prevent dislocation after hip replacement. Orthop. J. China. 2012;20:650-1.

28. Liu Y, Li X, Hao Z, Fan J. The effect of suturing the external rotator combined with different methods to reconstruct the joint capsule on the dislocation in total hip arthroplasty via the posterolateral approach. Clin J Med Off. 2018:46:1093-4.

29. Wang G, Lin J, Li Z, Lin Q. Comparison of two methods of posterior capsule reconstruction upon post-operative hip disloca- tion following primary total hip arthroplasty. J. Pract. Orthop. 2015;21:9-11.

30. Spaans EA, Spaans AJ, van den Hout JA, Bolder SB. The result of transmuscular versus transosseous repair of the posterior capsule on early dislocations in primary hip arthroplasty. Hip Int. 2015;25:537-42.

31. Moon JK, Kim Y, Hwang KT, Yang JH, Kim YH. The incidence of hip dislocation and suture failure according to two different types of posterior soft tissue repair techniques in total hip arthroplasty: a prospective randomized controlled trial. Int Orthop. 2018:42:2049-56.

32. Brooks PJ. The dislocator, early and late: the 3 am phone call. Orthopedics. 2011;34:e476-8.

33. Horwitz, B. R. et al. sA prospective randomized comparison of two surgical approaches to total hip arthroplasty. Clin Orthop Relat Res 154-163 (1993).

34. Paterno SA, Lachiewicz PF, Kelley SS. The influence of patient-related factors and the position of the acetabular component on the rate of dislocation after total hip replacement. J Bone Jt. Surg Am. 1997;79:1202-10. 
35. Masonis JL, Bourne RB. Surgical approach, abductor function, and total hip arthroplasty dislocation. Clin Orthop Relat Res. 2002:46-53. https://doi.org/ 10.1097/00003086-200212000-00006.

36. Woolson ST, Rahimtoola ZO. Risk factors for dislocation during the first 3 months after primary total hip replacement. J Arthroplast. 1999;14:662-8.

37. Bourne RB, Mehin R. The dislocating hip: what to do, what to do. J Arthroplast. 2004;19:111-4.

38. Ekelund A, Rydell N, Nilsson OS. Total hip arthroplasty in patients 80 years of age and older. Clin Orthop Relat Res. 1992:101-6.

39. Weber M, Cabanela ME, Sim FH, Frassica FJ, Harmsen WS. Total hip replacement in patients with Parkinson's disease. Int Orthop. 2002;26:66-8.

40. Palan J, Beard DJ, Murray DW, Andrew JG, Nolan J. Which approach for total hip arthroplasty: anterolateral or posterior? Clin Orthop Relat Res. 2009;467:473-7.

41. Lewinnek GE, Lewis JL, Tarr R, Compere CL, Zimmerman JR. Dislocations after total hip-replacement arthroplasties. J Bone Jt. Surg Am. 1978;60:217-20.

42. Amlie $E_{1}$ Høvik $\varnothing$, Reikerås $O$. Dislocation after total hip arthroplasty with 28 and 32-mm femoral head. J Orthop Traumatol. 2010;11:111-5.

43. Soong M, Rubash HE, Macaulay W. Dislocation after total hip arthroplasty. J Am Acad Orthop Surg. 2004;12:314-21.

44. Sun $X$, et al. The effect of posterior capsule repair in total hip arthroplasty: a systematic review and meta-analysis. BMC Musculoskelet Disord. 2020;21:263.

45. Berry DJ, von Knoch M, Schleck CD, Harmsen WS. The cumulative long-term risk of dislocation after primary Charnley total hip arthroplasty. J Bone Jt. Surg Am. 2004:86:9-14.

46. Bottner F, Pellicci PM. Review: posterior soft tissue repair in primary total hip arthroplasty. Hss j. 2006;2:7-11.

47. Zhou Y, et al. Is soft tissue repair a right choice to avoid early dislocation after THA in posterior approach? BMC Surg. 2017;17:60.

48. van Stralen GM, Struben PJ, van Loon CJ. The incidence of dislocation after primary total hip arthroplasty using posterior approach with posterior softtissue repair. Arch Orthop Trauma Surg. 2003;123:219-22.

49. Sioen W, Simon JP, Labey L, Van Audekercke R. Posterior transosseous capsulotendinous repair in total hip arthroplasty : a cadaver study. J Bone Jt. Surg Am. 2002;84:1793-8.

50. Osmani O, Malkani A. Posterior capsular repair following total hip arthroplasty: a modified technique. Orthopedics. 2004;27:553-5.

\section{Publisher's Note}

Springer Nature remains neutral with regard to jurisdictional claims in published maps and institutional affiliations.

Ready to submit your research? Choose BMC and benefit from:

- fast, convenient online submission

- thorough peer review by experienced researchers in your field

- rapid publication on acceptance

- support for research data, including large and complex data types

- gold Open Access which fosters wider collaboration and increased citations

- maximum visibility for your research: over $100 \mathrm{M}$ website views per year

At $\mathrm{BMC}$, research is always in progress.

Learn more biomedcentral.com/submissions 